Article

\title{
Empirical Identification of Latent Classes in the Assessment of Information Asymmetry and Manipulation in Online Advertising
}

\author{
Katarzyna Sanak-Kosmowska *(D) and Jan W. Wiktor *(D) \\ Department of Marketing, Cracow University of Economics, 31-510 Cracow, Poland \\ * Correspondence: sanakk@uek.krakow.pl (K.S.-K.); jan.wiktor@uek.krakow.pl (J.W.W.)
}

Received: 12 September 2020; Accepted: 17 October 2020; Published: 20 October 2020

\begin{abstract}
This study's purpose was to perform an identification analysis of the latent class in assessing information asymmetry and manipulation in online advertising. The title problem fits into the current research on sustainability with the focus on sustainable advertising and the role of modern marketing. This article presents the results of a quantitative study $(\mathrm{N}=138)$ conducted among young Poles. The obtained data were subjected to latent class analysis, which allowed for three groups of respondents to be distinguished. It turned out that the respondents differ from each other in terms of susceptibility to manipulation by online advertising and the awareness thereof, which is clearly distinguished by hidden variables. Therefore, in the discussion on information asymmetry in advertising, we should take into account the obvious demographic variables and the factors that respondents often do not declare in surveys and interviews.
\end{abstract}

Keywords: online marketing; persuasion; manipulation; latent class analysis

\section{Introduction}

This article's purpose is to perform an experiential identification analysis of the latent class in assessing information asymmetry and manipulation in online advertising. This purpose relates to research studies on the impact of advertising on consumer behavior. In a broader context, the title problem is part of the trend of research on the concept of sustainability. One of the research areas is Sustainable Marketing [1,2] and Sustainable Advertising. Sustainable Advertising-by analogy with the essence of the concept of sustainability-refers to a sustainable manner in which a company communicates information to the markets based on transparency, information symmetry, and straightforward interpretation; messages are not misleading and do not violate consumer protection rights or business ethics principles. This advertising character ensures meeting the sender's sales and communication-related targets (a company's growth) and simultaneously satisfies customers' information-related needs during the buying process. In addition, it contributes to building trust in market relationships and creating and multiplying relationships and social capital. Moreover, it encourages a company's marketing reorientation [3,4] and engagement in a broad sustainability movement through CSR (corporate social responsibility) and co-participation in creating responsible and sustainable consumption [5,6].

The problem addressed in this paper is significant and innovative in its cognitive dimension. It is an attempt to fill a research gap that is visible in literature and research studies. This gap results from the lack of theoretical reflection on and empirical knowledge (evidence-based theory) about assessing information asymmetry and manipulation in online advertising. Advertising is discussed in the relatively new theoretical context of asymmetry and manipulation. Based on latent class analysis, empirical research focuses on the empirical identification of relationships between these categories. 
Research on advertising focuses on the general aspects of its significance for a company (an instrument for implementing a marketing strategy) and consumers (advertising as a source of purchase information, creating brand needs and preferences, impact on consumer market behavior and advertising ethics), specific issues, such as the impact of advertising on children $[7,8]$, generation $Y$, or older people (the segment of silver consumers) $[9,10]$ or the significance and effectiveness of particular types of advertising and communication channels, and the role of particular online advertising tools, including social media [11-13]. Many research studies are fragmentary. There is a lack of general (basic) research on online advertising and its impact on e-consumers' behavior through manipulation. The issue of manipulation in particular communication tools and channels is not given much attention in the literature [14,15]. A significant impact of advertising on consumer behavior is unquestionable. However, the issue of e-consumers' susceptibility to manipulation and the awareness of this impact remains to be an unexplored research area. It is also significant in its practical dimension due to social and ethical reasons.

The nature of the presented problem and the diagnosed research gap determine the specific goal of this research-we seek answers to the following questions, which are empirically formulated and based on methodical rigors:

- Are e-consumers aware of information asymmetry and manipulation in advertising?

- Do latent data affect e-consumers' (respondents') declared answers, and how?

Identifying these variables based on latent class analysis confirms the innovative character of this study and its contribution to research on advertising in the context of Sustainable Marketing and the concept of sustainability.

\section{Previous Literature and Research}

The research gap and its context relate to two issues. Firstly, advertising in the web environment is becoming an increasingly important form of companies' marketing communication. It results from global digital transformations, the communication and information revolution, and e-business expansion, including e-marketing and e-commerce. Marketing digitalization trends are reflected in a shift from marketing 1.0 to marketing 4.0 [16-18], the Fourth Industrial Revolution [19], the creation and development of the network society or information society, and digital humans [20-26]. Secondly, online advertising's impact on consumer behavior results from its essential functions, including a persuasive function. Under the conditions of developed markets and the excessive supply of goods in practically all sectors, the persuasive function of exerting influence dominates all other functions. Persuasion is the core activity of advertisers, and the range of possible and applied forms of affecting recipients' market decisions becomes increasingly diverse [15,27-35]. It is stimulated by the web environment, its attributes, and the development of ICT (information and communications technology) as well as information and communication apps [16,18,36-40]. In the theoretical justification of the problem and the research gap's characteristics, we stress mutual relationships between the persuasive function of online advertising, information asymmetry, and consumer behavior manipulation. This represents a new approach to advertising in the context of information asymmetry and consumer manipulation. These relationships are described based on a literature review.

The fundamental objective of advertising is to ensure a company's continuous information-related presence on the market $[17,35,41-43]$. The hypermedia computer environment $[18,37,44]$ provides perfect conditions for this. It is commonly seen from two perspectives: sales and communication $[29,35,36,44-47]$. They are implemented through informative, persuasive, and competitive functions.

Because of this paper's objective and the research gap, we stress the fundamental function presented in the title problem-persuasion, i.e., the impact of advertising on consumer market behavior. The persuasive function of advertising manifests itself in verbal and non-verbal messages and the way that communicated messages are allocated in media (organizational components, e.g., time, place, 
and frequency of transmissions). All these components—directly, indirectly, and latently-aim to affect consumer behavior and market decisions [30,34,48-52]. We stress these elements because they are the subject of our research on internet users' perception of advertising and the identification of latent variables in advertising perception $[27,31,53-55]$.

Persuasion in advertising is employed through diverse forms of encoded messages, creation strategies, and the ways that advertising is allocated in time and space in media $[7,15,17,29,33,35,41-43,45,47,56,57]$. Advertising presents simplified and usually symbolic characteristics of things offered for sale. Its messages can be incomplete, ambiguous, and latent, and can be presented in a specific social, psychological, and cultural context as well as a specific time framework. Each of these components can contribute to information asymmetry between advertisers and advertisees.

Information asymmetry (IA) indicates differences in the amount of information possessed by participants in market relationships. In a way, it is an information game in which the rules are set by the party "equipped" with more information [58-61]. The concept of information asymmetry can represent an interesting perspective in research on advertising, and has contributed to a series of debates conducted by G.A. Akerlof, M. Spence, and J. Stieglitz $[60,62,63]$ in the fields of economics, managerial economics, market research, market participant behavior, and market regulation [64-71]. The essence of information asymmetry is the lack of balance or symmetry in the information or knowledge possessed by market exchange participants, sellers, advertisers, advertisements, or potential customers. The market of excessive supply - which can be referred to as the market of "manipulative supply" -and the market of stiff competition in practically all business sectors place sellers in an advantageous position in their relationships with consumers in terms of information possessed. Such a market reveals the nature and significance of advertising's persuasive function $[15,28,69,72,73]$.

In the classical IA model, the sender of information [58] possesses considerably more sales information than the recipient of messages-potential customers. The sender is also well aware of the "quality" of information with respect to its encoding in ads, its content and symbolic character, the communication context, the equivalence of meanings, and other components of a creative advertising strategy. From the perspective of advertisements, this indicates the lack of quality information required to make a purchase decision.

The effects of information asymmetry are multivariate and significant. They relate to circumstances - at a highly general economic theory level—that reflect market inefficiencies and ineffective resource allocation $[58,60,67,74]$. Referring to the objectives of this paper and the research gap, we stress that they lead to the temptation to abuse information (moral hazard) on the part of advertisers, as well as to customers' wrong choices of purchased products (adverse selection) [58,74]. G. A. Akerlof and R. J. Shiller presented the effects of information asymmetry. They attributed a manipulative character to advertising [75]. They believe that advertising has a significant impact on the contemporary economy, referred to as the Economics of Manipulation and Deception. The authors use a metaphor referring to advertising-related relationships between sellers and consumers: Phishing for Phools $[75,76]$. This view has a special meaning in the context of society's criticism of advertising and ethics in advertising [77]. Simultaneously, it refers to the characteristics of the research gap mentioned at the beginning of the paper.

One of the numerous effects of information asymmetry in advertising is the possibility of consumer behavior manipulation. Manipulation is the second significant variable, and it allows for diagnosis of the research gap in its theoretical and empirical dimensions. The essence and nature of manipulation as a method of exerting influence in interpersonal and social relations and affecting people's behaviors and attitudes are widely discussed in many disciplines of the social sciences. Without reference to epistemological problems in the context of the theoretical justification of the problem, it was assumed that the essential characteristics of manipulation include hiding the objectives and intentions of the perpetrator, deriving benefits from the other party's incomplete knowledge and lack of awareness, hiding a given action by distracting attention from the sender of a message, deception, 
fragmented information, benefiting from somebody else's weaknesses, and creating conditions for such situations $[27,28,31,48,50,51,54,55,78]$.

Manipulation indicates the lack of transparency (or incomplete transparency) of an entity's intentions affecting the other party's behavior, which leads to a lack of awareness or misinformation through information asymmetry. Taking advantage of an advantageous position resulting from possessing information and hiding actual intentions is frequently accompanied by distracting attention by emphasizing details of secondary importance. Such behaviors are intentional and premeditated, are based on careful planning, and allow for possible losses (various economic and social costs); they are intentional misleading and based on information games using incomplete, ambiguous, and inaccurate information, thus reflecting information asymmetry in mutual communication $[20,27,48,54,79]$. To no small degree, the indications of manipulation can apply to how advertising affects consumers. Earlier research, which was conducted from the perspective of management and psychology and focused on manipulation in advertising, concentrated on the situational factors affecting susceptibility to manipulation [1], individual differences conditioning susceptibility [80], and the manipulative character of particular forms and content of advertising (e.g., [14,53,81]). A significant trend in research is the investigation of susceptibility to advertising among children, youth, and older people $[8,10,72,82]$.

Based on a literature review, the theoretical framework of the presented problem allowed for the identification of a research gap, the presentation of its justification, and the setting of specific research objectives. It facilitated the creation of a model and the empirical identification of latent classes in assessing communication asymmetry and manipulation in online advertising.

\section{Methods and Materials}

\subsection{Method}

Research on groups of students is a kind of reference to the book by Akerlof and Shiller, Phishing for Phools [75]. In their dedication of the book, the authors write that this work, which shows the mechanisms of the economy of manipulation and deception, is also addressed to young people, who are only thinking about choosing a future profession that could give them full satisfaction and a chance to realize their careers. Our research group meets this condition. The presented studies had a pilot character, mainly performing the functions of substantive and methodological verification of the research tool [83]. The online version of the survey was distributed using the Google Forms tool. Filling out the form was encouraged by teachers and students using social networking sites, especially informal discussion groups on Facebook. The students were able to complete the survey at any time and in any place. They could also stop providing answers at any time, thus canceling the questionnaire [84]. Completion of the survey took an average of 12 minutes.

The questionnaire of choice consisted of five parts and a few demographic questions:

1. Introductory questions about experiences and ways of using the Internet regarding the frequency and extent of social networking, online shopping, and goals and rationale for using the Internet.

2. Rating the intentions of advertisers and the advertising message in light of their own experience and presence in the world of online advertising.

3. Evaluation of the impact of advertising on the e-consumer in the context of individual and social assessments.

4. The subjective perception of the role of advertising in the process of online shopping.

5. Evaluation of respondents' knowledge in the field of online marketing and their digital competences.

The introductory questions aimed to discover how and how often the students used the Internet, used social networking sites, and made purchases online. The respondents made the assessments on a scale of 1-5, indicating the extent to which they agreed with the authors' criteria. 
In the second part of the research tool, the respondents assessed advertisers' intentions and advertising messages. In particular, they assessed the credibility of the various forms of online advertising, such as online video advertising, online reviews, sponsored articles, banner ads, websites, and bloggers' and celebrities' opinions.

In parts three and four of the questionnaire, the respondents were asked about the subjective sense of the influence of online advertising on making purchasing decisions and the sense of informational advantage that advertisers have over them. The respondents also referred to the content of online media advertising: consistency, uniformity, and general manipulativeness. The assessment of information asymmetry in online advertising was also a key research project category.

The fifth part of the questionnaire was part of the preliminary diagnosis of the respondents' digital competences and their knowledge of Internet marketing.

\subsection{Participants}

Table 1 shows the characteristics of the study group. In the online survey, women accounted for $79 \%$ of the sample, while $21 \%$ were men. The selection of the sample was purposeful. The respondents were dominated by persons aged $18-25$ years.

Table 1. Selected characteristics of the students $(\mathrm{N}=138)$.

\begin{tabular}{|c|c|c|c|}
\hline \multicolumn{2}{|c|}{ Selected Characteristics of the Students } & \multicolumn{2}{|c|}{ Number of Participants and PercentAges } \\
\hline \multicolumn{2}{|c|}{ Total } & 138 & $100 \%$ \\
\hline \multirow{2}{*}{ Sex } & Female & 109 & $79 \%$ \\
\hline & Male & 29 & $21 \%$ \\
\hline \multirow{2}{*}{ Age } & $18-25$ & 132 & $96 \%$ \\
\hline & $26-35$ & 6 & $4 \%$ \\
\hline
\end{tabular}

The respondents are active Internet users. A total of $100 \%$ of the respondents declared daily use of the Internet, and $69.5 \%$ are practically always online. A total of $99.2 \%$ of the respondents owned accounts and actively used social networking sites: 99.2\% used Facebook, $84.8 \%$ used Instagram, $31.8 \%$ had LinkedIn accounts, $84.78 \%$ used Snapchat, and $84.7 \%$ had YouTube accounts. A total of $96.3 \%$ of the respondents used social networking sites several times a day, and $48.5 \%$ stayed online practically always. This respondents' descriptive characteristics indicate that the surveyed young people actively and intensively use the Internet, including social networking sites.

\section{Results}

\subsection{Data Analysis}

In such disciplines as sociology, economics, or psychology, it is easy to apply statistical methods to study dependencies or relationships between the variables under study when we deal with observable, measurable characteristics. A problem arises in the case of hidden features, i.e., those that cannot be directly measured and whose evaluation is subjective. Examples of such features are the variables examined in this article. Analysis of hidden classes is a statistical method used to explore the subtypes of interrelated multidimensional categorical characteristics. A latent class defines a particular abstract feature-for example, a preference for forms of advertising or a characteristic that cannot be observed directly. Thus, if the hidden construct has a step structure, i.e., a feature is qualitative and has some variants within a variable, each feature can be treated as a latent class.

Latent class analysis is a statistical technique for the analysis of multivariate categorical data. When observed data take the form of a series of categorical responses as, for example, in public opinion surveys, individual-level voting data, studies of inter-rater reliability, or consumer behavior and decision-making, it is often interesting to investigate sources of confounding between the observed 
variables, identify and characterize clusters of similar cases, and approximate the distribution of observations across the many variables of interest. Latent class models are a useful tool for accomplishing these goals [85]. This method's theoretical basis was formulated in 1950 by Lazarsfeld, who discussed the concept of multidimensional data analysis in detail [86]. Lazarsfeld then continued his work [87], and many other statisticians followed in his steps [88].'However, a special role was played by the work of Goodman, who implemented the method of maximum likelihood estimation for the needs of the model parameters in the analysis of latent classes [89]. Contemporary studies analyzing the problems of latent classes in depth include the work of Collins and Lanza [90]. Currently, latent class analysis is widely used in different fields of social science research, e.g., in educational assessment, cognitive and personality psychology, social surveys of life satisfaction, deviant behavior, and social attitudes, and in epidemiological and longitudinal studies [91,92].

To achieve the research objective, we decided to resort to latent class analysis. Figure 1 presents the particular phases of the analysis of the obtained data. The model was built on the basis of selected variables referring to "mistrust" and, therefore, a subjective sense of information asymmetry and manipulation using the BayesLCA package in the R environment (v.3.4) [93]. For this purpose, the obtained results were recoded into binary data-on the basis of responses on a Likert scale, the answer " 0 " indicates an answer below the median for a group, while the answer " 1 " indicates an answer above the median. In the course of the analysis, four dependent variables with the highest weighting were identified (Y61, Y62, Y63, Y64). Detailed results are shown in Table 2.

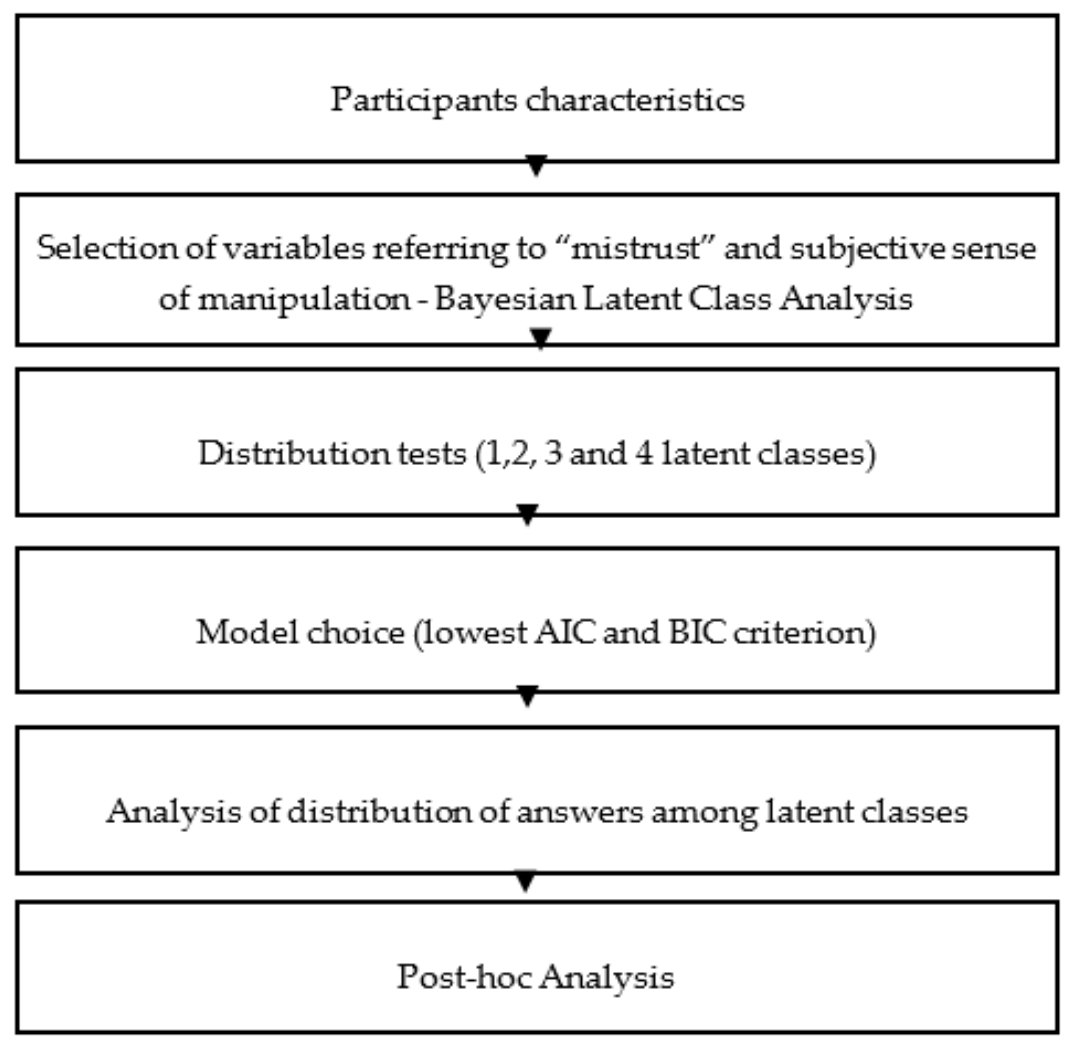

Figure 1. Phases of the analysis of the obtained data.

The applied BayesLCA package in the R environment (v.3.4) allows for an analysis of exclusively binary data. It was sufficient in identifying dependent variables, but to facilitate an analysis of the entire data structure (expressed in a scale from 1 to 5 ), the remaining analyses were conducted using the polCA package. The starting point for the analysis of the results of the study was to verify the prevalence of latent classes. Latent class analysis for ordinary encoded data was used for the statistical analysis procedure using the R software (v.3.4) [93]. In this way, we examined how people form clusters 
based on the number of latent classes. A distribution of one, two, three, or four classes was tested (Table 3). On the basis of the analysis of the differentiation of clusters of individual variables and the analysis of the Akaike information criterion (AIC) and Bayesian information criterion (BIC) values, we found three latent classes.

Table 2. Dependent variables referring to the sense of asymmetry of information and manipulation.

\begin{tabular}{cc}
\hline Variable & Variable Characteristics \\
\hline Y 61 & "I have the impression that my personal data are often used to create per-sonalized offers" \\
Y 62 & "I feel manipulated by online advertising" \\
Y 63 & "I leave online traces that can be used to manipulate my behavior" \\
Y 64 & "Advertising has an information advantage over me" \\
\hline
\end{tabular}

Table 3. Models (segmentations) of the latent class analysis adapted to the variables referring to the sense of asymmetry of information and manipulation.

\begin{tabular}{ccc}
\hline Template & AIC & BIC \\
\hline One-cluster Model & 1583.32 & 1630.156 \\
Two-cluster Model & 1499.838 & 1596.438 \\
Three-cluster Model & $\mathbf{1 4 4 9 . 6 7 5}$ & $\mathbf{1 5 9 6 . 0 3 8}$ \\
Four-clusters Model & 1452.034 & 1648.16 \\
\hline
\end{tabular}

Note: $\overline{\mathrm{AIC}}=$ Akaike information criterion; BIC = Bayesian information criterion.

The studied model adopted the following values: Function: $\mathrm{f}<-$ cbind[Y61, Y62, Y63, Y64] 1; Model calculation: lc3 <- poLCA[f, PL_online, nclass $=3$, maxiter $=5000$, graphs $=$ TRUE, tol $=1 \times 10^{-10}$, na.rm $=$ TRUE, probs.start $=$ NULL, nrep $\left.=100\right]$. The tested model was characterized by the following alignment parameters: Estimated class population shares amounted to 0.2079, 0.5917, and 0.2004 , and predicted class memberships (by modal posterior probability) amounted to 0.1957, 0.6159 , and 0.1884 . There were 88 residual degrees of freedom. Figure 2 presents model fitting for the three latent classes.

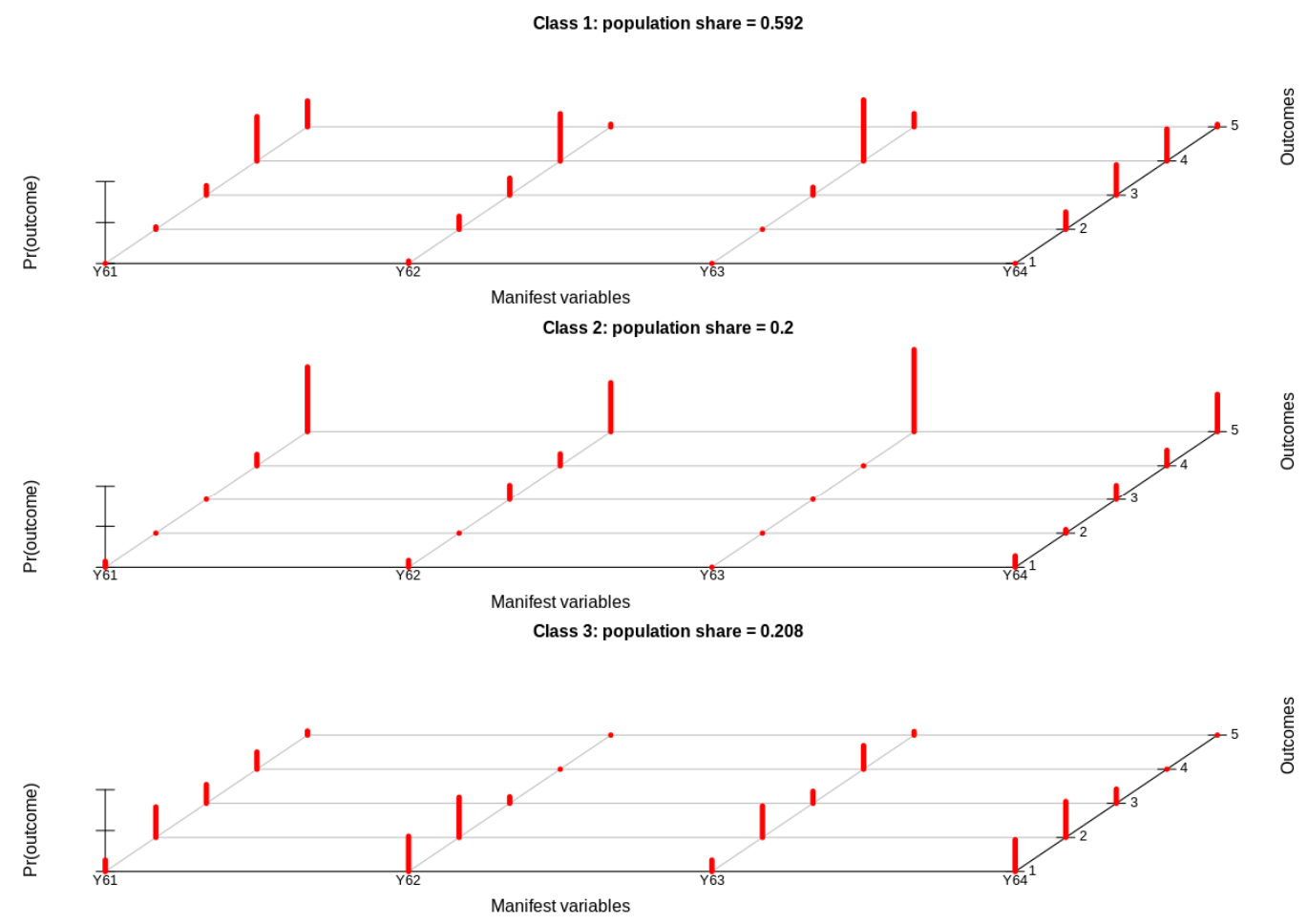

Figure 2. Model fitting for the three latent classes of participants $(\mathrm{N}=138)$. 


\subsection{Empirical Findings}

On the basis of the obtained results, it is possible to make a preliminary characterization of the probability of occurrence of particular variables among representatives of particular latent classes. Detailed results are shown in Table 4.

Table 4. Characteristics of latent classes.

\begin{tabular}{|c|c|c|}
\hline Latent Class & Proposed Name & Characteristics of Probability \\
\hline 1 & $\begin{array}{l}\text { Aware } \\
\mathrm{N}=85\end{array}$ & $\begin{array}{l}\text { High awareness of the use of personal data, the sense of } \\
\text { manipulation by online advertising, and leaving digital } \\
\text { footprints, and a moderate awareness of the information } \\
\text { superiority of advertising. }\end{array}$ \\
\hline 2 & $\begin{array}{l}\text { Careful and experienced } \\
\qquad N=26\end{array}$ & $\begin{array}{l}\text { Very high awareness of the use of personal data, a high sense of } \\
\text { manipulation by online advertising, a very high awareness of } \\
\text { leaving digital footprints, and greater awareness of the } \\
\text { information superiority of advertising. }\end{array}$ \\
\hline 3 & $\begin{array}{l}\text { Inexperienced } \\
\qquad \mathrm{N}=27\end{array}$ & $\begin{array}{c}\text { Low awareness of personal data use, low sense of manipulation } \\
\text { by online advertising and leaving digital footprints, and low } \\
\text { awareness of advertising information superiority. }\end{array}$ \\
\hline
\end{tabular}

The next stage of the study analyzed responses to the question with regard to the proposed assignment of hidden classes. The result of these actions was the identification of statistically significant variables that allowed the prediction of the characteristics correlating with belonging to the proposed class. They can be assigned to the following categories:

1. Professionalization of Internet use (Y18, Y20).

2. Trust in social proof of rightness ( $\mathrm{Y} 22, \mathrm{Y} 28, \mathrm{Y} 32, \mathrm{Y} 53)$.

3. Attitude towards online advertising (Y38, Y40, Y43, Y44, Y46, Y86).

4. Attitude towards personalization of online advertising content (Y49, Y56, Y59, Y67).

5. Willingness to share personal information online (Y77, Y80).

6. Attitude towards state intervention in the regulation of online advertising (Y104).

By analyzing the response schedules, a qualitative characterization of the representatives of the various hidden classes can be provided. In the case of the latent class tentatively determined as "inexperienced", we deal with people who actively use the Internet, but use it for professional purposes to a lesser extent (Y18, compared to representatives of other groups). They are also persons that have a relatively lower confidence in online reviews (Y22, Y28); however, they are more aware of the impact of influencers (Y53). The "inexperienced" are less aware of the manipulative nature of advertising (Y43) and its impact on society's materialism (Y44). Their attitude toward personalizing online advertising content, particularly with respect to search history in search engines, was rather positive (Y59). These are often people who share their personal information by filling out quizzes and questionnaires online (Y77). Interestingly, compared to representatives of other groups, the "inexperienced" were the least enthusiastic about the issue of strict state intervention in the market for online advertising (Y104).

The largest group of respondents $(\mathrm{N}=85)$, described as the "conscious", were also active Internet users, and also used it for professional reasons. These people have confidence in the advice of friends and other users of social media, and tend to be under a moderate impact of influencers' opinions. Those that are "aware" of the tricks used by advertisers (Y46) are also conscious of their negative impact on society (Y44). They are aware of the mechanisms of the personalization of online content (Y56) and are in favor of state intervention in the advertising market (Y104).

There is also the characteristic of responses from representatives of the "cautious and experienced". In this case, the analysis of answers indicates that we deal with the most advanced users whose professional work takes place in a virtual environment (Y18, Y20). These people are aware of the informative advantage of skillful Internet use. They treat the opinions of other Internet users as the most 
reliable source of online information (compared to other tools, e.g., websites, banner ads, and others), they use content personalization to benefit from it, and they share their personal data in case there are any benefits (e.g., membership in a loyalty program; Y80). In summary, these people were aware of not only the information advantage held by the advertisers, but also the benefits for e-consumers who used it skillfully.

With regard to the category of questions verifying the degree of professionalization of Internet use, two variables turned out to be statistically significant: Y18 ("Internet access is essential for the realization of my daily tasks") and Y20 ("Internet access makes my work easier"). They are presented in Figure 3. The representatives of all identified latent classes use the Internet, which helps them perform daily responsibilities, but in the case of the "careful and experienced" cluster, the observed domination is considerable. The second statistically significant variable was the opinion of other users on the Internet as a valuable source of information about products. In this case, the distribution of responses for all the analyzed groups was shifted to the right, but differences can be observed in the percentage distribution of the answers "no opinion" and "yes".

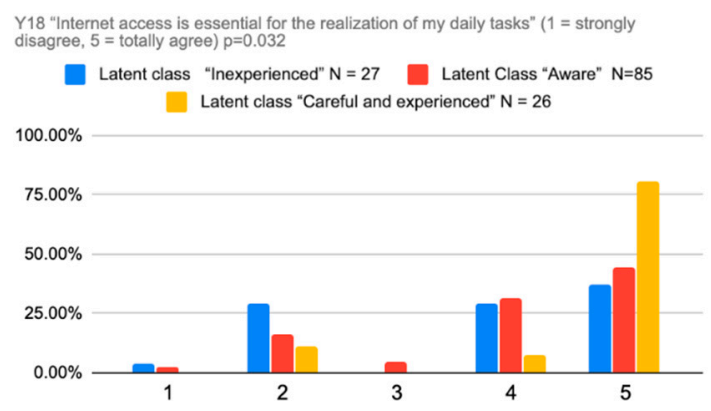

(a)

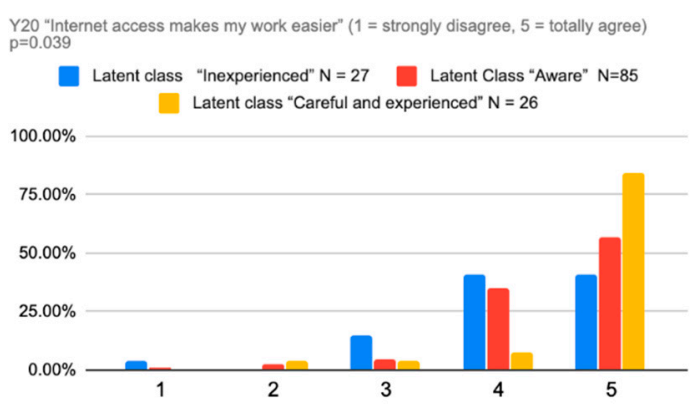

(b)

Figure 3. Professionalization of Internet use-answer differences among three latent classes: (a) Y18- "Internet access is essential for the realization of my daily tasks", (b) Y20_- Internet access makes my work easier".

Another category refers to trust in the social proof of rightness. Social proof is to be understood as the principle introduced by Cialdini, according to which an individual who does not know which decision or view is correct (which can depend on various factors) conforms to the decisions or views of the majority of the group members [27,94]. With regard to this category, four questionnaire indicators turned out to be statistically significant (Figure 4): Y22 ("Opinions of other Internet users are a valuable source of product knowledge"), Y28 ("The most reliable sources of online information are the opinions of my friends in social media:), Y32 ("The most reliable sources of online information are the opinions of the other Internet users"), and Y53 ("My purchase decisions are affected by opinions from influencers"). The representatives of all the analyzed groups highly value the opinions of other Internet users and regard them as a reliable source of product knowledge. The representatives of the "aware" and "careful and experienced" classes stress a special role of their friends' opinions in social media-more frequently than the "inexperienced", users, they chose the answer "totally agree".

Six variables belonging to the category "Attitudes towards online advertising" were statistically significant (Y38, Y40, Y43, Y44, Y46, Y86). Interestingly, the representatives of the "careful and experienced" class, more frequently than the representatives of other classes, gave the answer "I don't know" to the question about humor and entertainment. In the cases of the remaining variables, differences in the distributions of answers were insignificant. However, attention should be given to answers to the question about the manipulative character of advertising (Y43: "Ads pretend to be informative, but they are just meant to persuade one to make a purchase"). In this case, the greatest reservations about online advertising were expressed by the "careful and experienced" class-nearly $85 \%$ of them answered "yes" or "totally agree", while in the case of "inexperienced" -nearly $56 \%$-and 
"aware", this was only 73\%. The observed caution and suspicion were also characteristic of variables Y44 and Y86. In this case as well, the distribution of answers given by the "aware" and "careful and experienced" classes shifted to the right. In the case of the statement "Ads are incomprehensible" (Y86), the distribution of answers between the particular classes seems to be complex-the answers "no" and "no opinion" prevail in all of them. The distribution of answers is presented in detail in Figure 5.

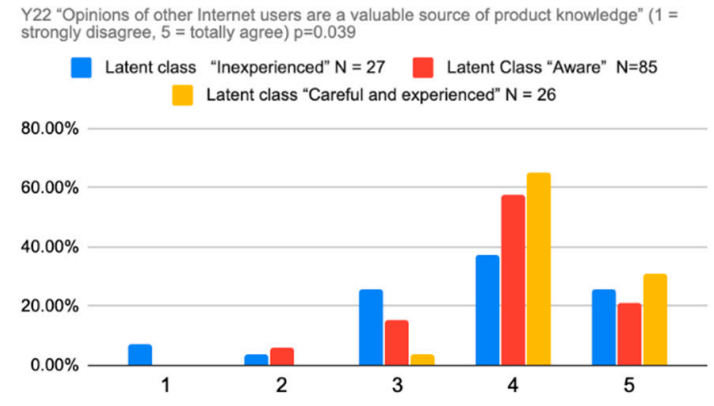

(a)

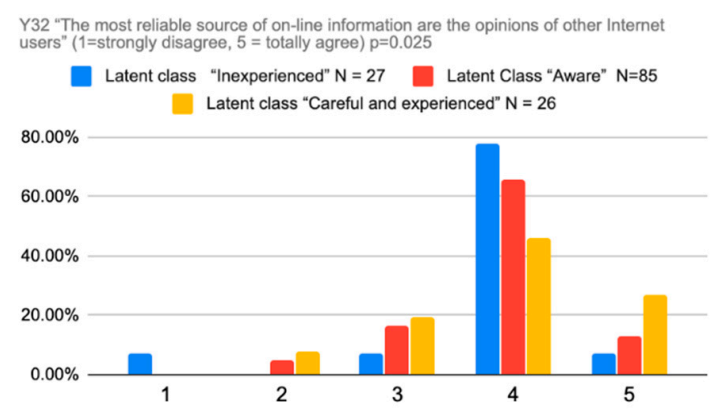

(c)

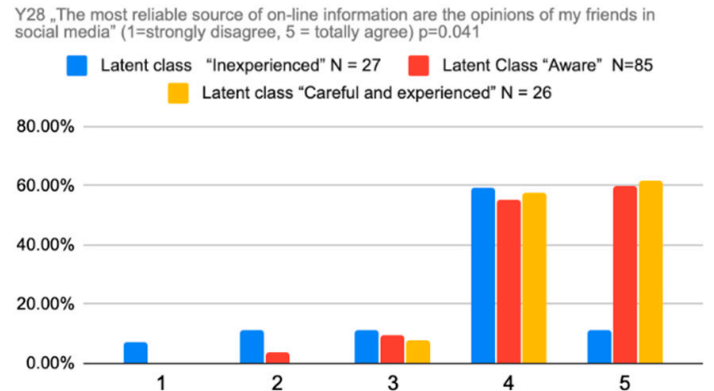

(b)

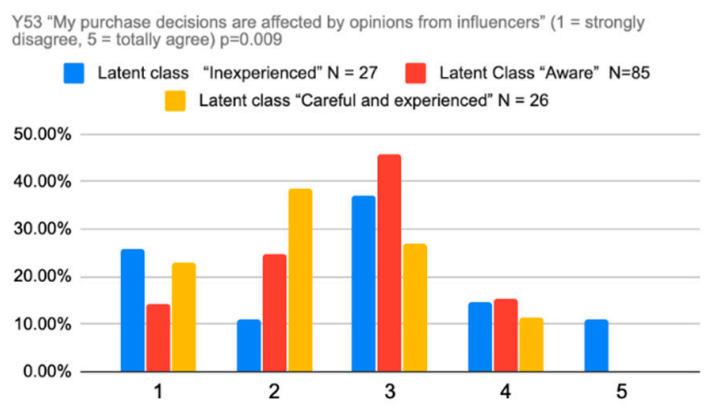

(d)

Figure 4. Trust in social proof of rightness-answer differences among four latent classes: (a) Y22 "Opinions of other Internet users are a valuable source of product knowledge"; (b) Y28 "The most reliable source of on-line information are the opinions of my friends in social media" (c) Y32 "The most reliable source of on-line information are the opinions of other Internet users"; (d) Y53 "My purchase decisions are affected by opinions from influencers".

Four variables were statistically significant for the category "Attitude toward personalization of online advertising content" (Y49, Y56, Y59, Y67). The distribution of answers for the particular classes is presented in Figure 6. In this context, attention should be given to the question about the impact of personalized newsletters on purchase decisions. More than half of the "careful and experienced" respondents (61.4\%) were aware of this impact; in the case of "inexperienced", this value was below $26 \%$, and in the "aware" class, it was $28 \%$. This indicates that the most experienced group of respondents is again the most aware of the possible impact.

In the case of variables categorized for the purpose of this paper, such as "Willingness to share personal information online", two of them were statistically significant. The overwhelming majority of respondents declared the intention to protect their personal data by not disclosing it while completing online quizzes and surveys. The largest number of "yes" answers was given by the representatives of the "inexperienced" class (30\%). In the case of disclosure of data while joining loyalty programs, the opposite situation was observed-nearly $70 \%$ of "careful and experienced" representatives disclosed their data in return for benefits from program participation. This indicates that more experienced individuals and those aware of possible consequences are encouraged to disclose personal data if they expect specific benefits. In turn, most "careful" representatives are not willing to disclose data in 
such situations (62\%). Therefore, it can be assumed that "aware" persons fear disclosing data under any circumstances because they are not aware of the consequences. The distribution of responses is presented in detail in Figure 7.

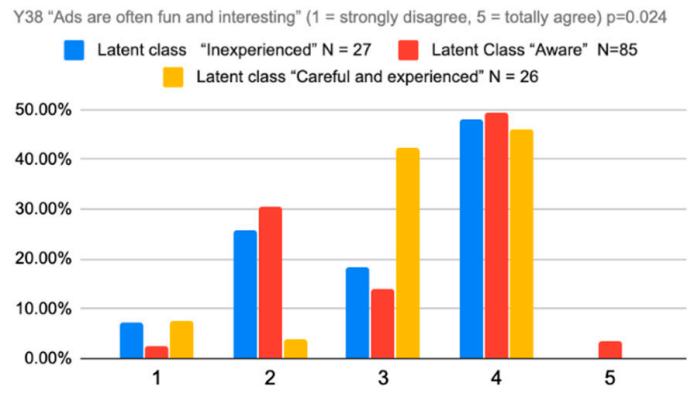

(a)

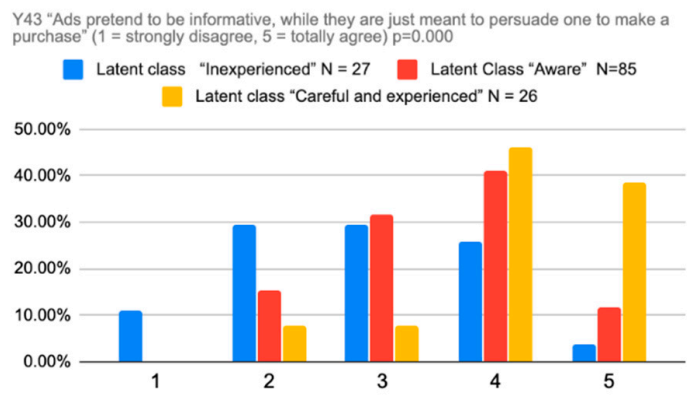

(c)

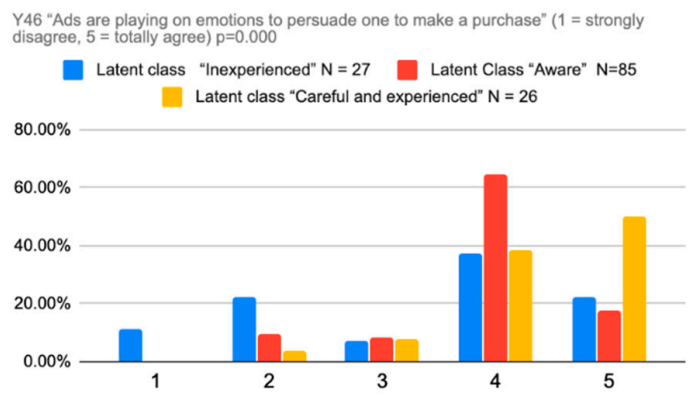

(e)

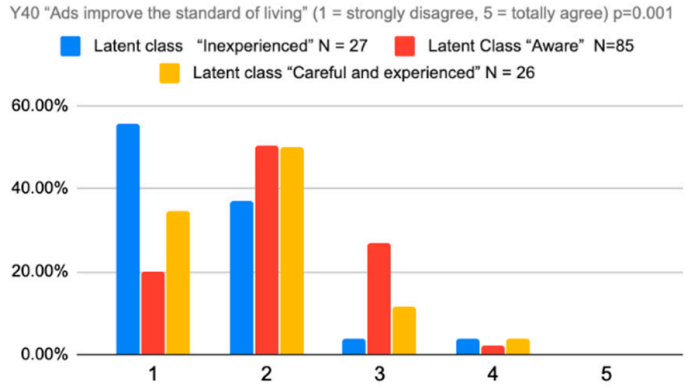

(b)

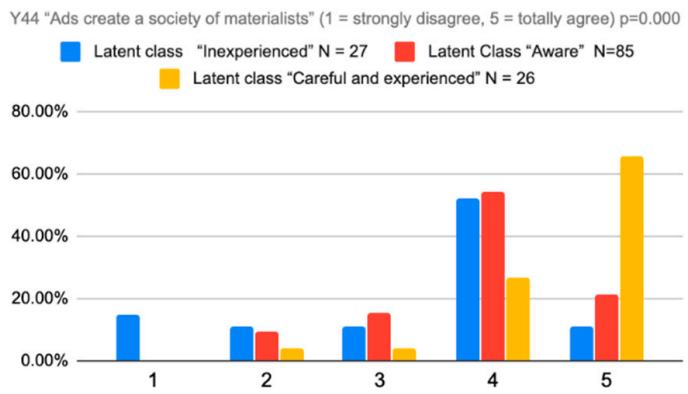

(d)

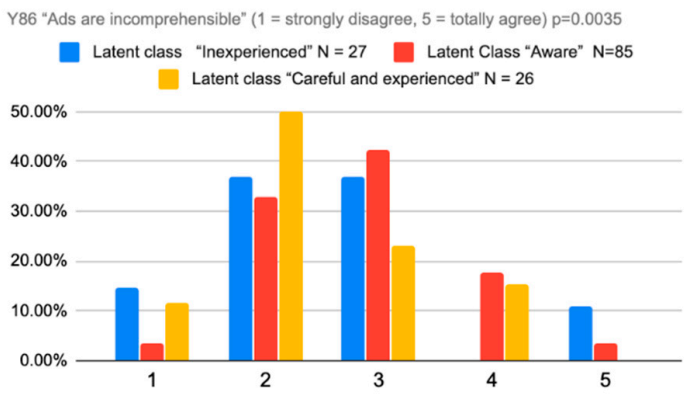

(f)

Figure 5. Attitudes towards online advertising-answer differences among six latent classes: (a) Y38 "Ads are often fun and interesting", (b) Y40 "Ads improve the standard of living", (c) Y43 "Ads pretend to be informative, while they are just meant to persuade one to make a purchase", (d). Y44, "Ads create a society of materialists" (e) Y46 "Ads are playing on emotions to persuade one to make a purchase", (f) Y86 "Ads are incomprehensible".

In the last category, "Attitude toward state intervention in the regulation of online advertising", only one variable turned out to be significant (Figure 8). All respondents were in favor of state intervention in the advertising market, and this idea was mainly supported by "careful and experienced" (81\%) and "aware" respondents (79\%).

The final stage of research differentiation was the analysis of the studied groups in terms of individual latent variables in order to check whether the individual groups differed. For this purpose, a Kruskal-Wallis test was used because the objective was to compare three groups of latent variables in terms of significant quantities. Contrary to expectations, only one variable (Y18: "Internet access is essential for my daily tasks") indicated that one group is clearly different from the others. As a result of 
the post-hoc analysis with the Conover-Inman test, statistically significant differences between the "inexperienced", the "careful and experienced" $(p<0.02)$, and the "conscious" $(p<0.005)$ groups were identified. This means, therefore, that despite the fact that we have only students among the respondents, using the Internet not only for entertainment but also daily tasks clearly differentiates the obtained answers. In this case, the differences may have a situational character and may be associated with the nature of the duties performed or with individual characteristics-for example, a sense of duty and diligence. For other variables, the analysis did not confirm the statistical significance. This, therefore, means that only the degree of professionalization of Internet use significantly differentiates the representatives of the particular classes.

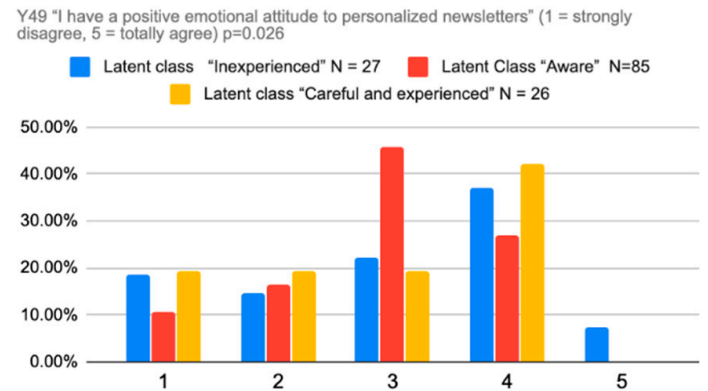

(a)

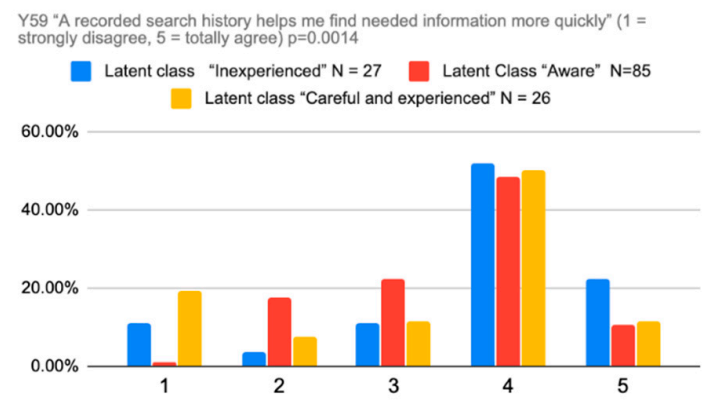

(c)

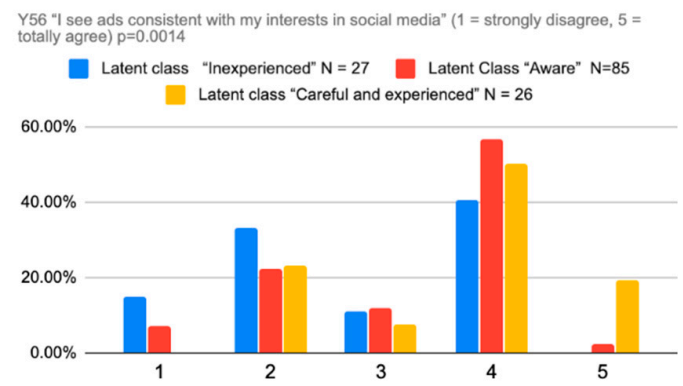

(b)

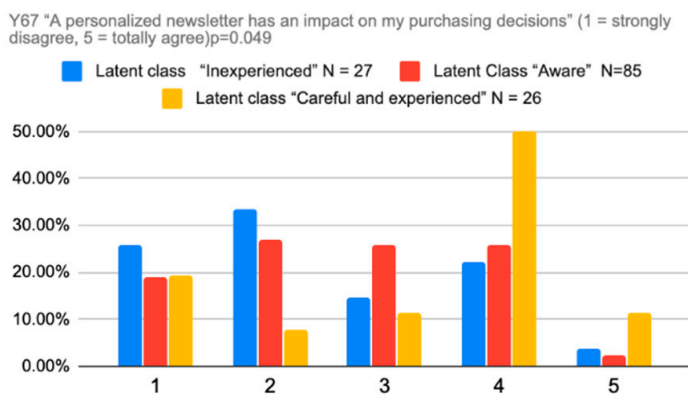

(d)

Figure 6. Attitude toward the personalization of online advertising content-answer differences among four latent classes: (a) Y49 “I have a positive emotional attitude to personalized newsletters", (b) Y56 "I see ads consistent with my interests in social media", (c) Y59 "A recorded search history helps me find needed information more quickly", (d) Y67 "A personalized newsletter has an impact on my purchasing decisions".

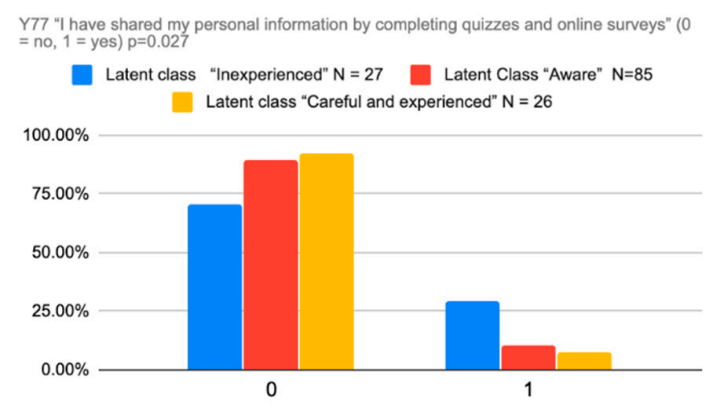

(a)

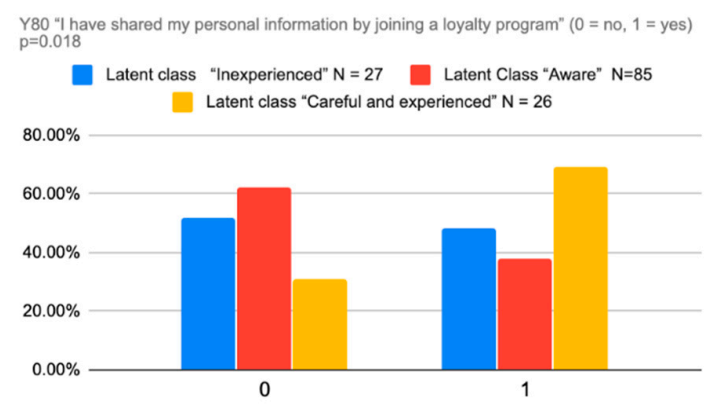

(b)

Figure 7. Willingness to share personal information online-answer differences among two latent classes: (a) Y77 "I have shared my personal information by completing quizzes and online surveys"; (b) Y80 "I have shared my personal information by joining a loyalty program". 


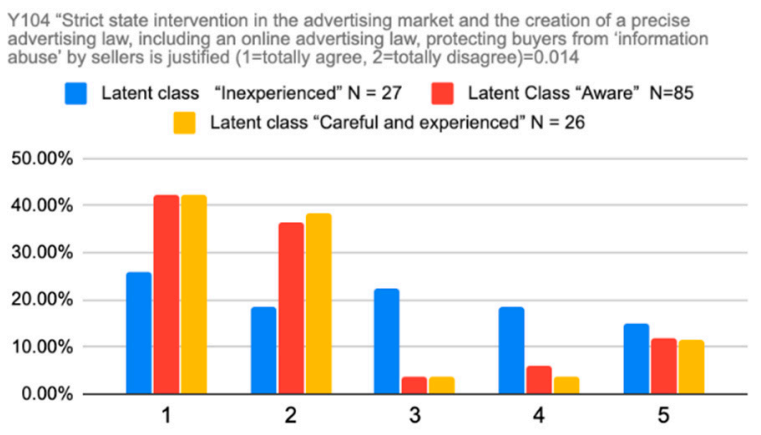

Figure 8. Attitude toward state intervention in the regulation of online advertising (Y104).

\section{Discussion}

The aim of this article was to empirically assess the forms and scale of information asymmetry in advertising and its consequences, which were expressed by the perception of manipulation of e-consumer behavior.

Based on latent class analysis, the research conducted here allowed us to categorize consumer behavior in the Internet environment into three groups of respondents with different levels of susceptibility to persuasion. For the first group, conventionally referred to as the "inexperienced", there is a high susceptibility to advertising, a clear "belief" in the message, and submissiveness to suggestions and ways of influence hidden in advertising. Its size constituted $19.6 \%$ of the surveyed population. To a large extent, this group of respondents corresponded to the characteristics of "fish"-a consumer in the concept of phishing according to G. A. Akerlof and R. J. Shiller [75]. For the second most numerous group of study participants $(61.6 \%)$, referred to as the "conscious", there is a characteristic awareness of informational risks in the online environment, including, in particular, the asymmetry of information in advertising messages and possible manipulation of behavior. Despite being aware of the manipulation, this group of respondents trusts the information in the advertisements and opinions published by other users in the virtual environment. In addition to the risks, they also see the benefits of online advertising for consumers. The third and last group, called the "cautious" $(18.8 \%)$, were respondents characterized by resistance to persuasion in advertising, low or insignificant sensitivity to stimuli contained in advertising, and clear criticism of the message. Importantly, according to the results of the post-hoc analysis, these people are clearly different from representatives of the other two groups in terms of how they use the Internet: The "cautious" people are much more likely to use it for business purposes and need it for their daily duties.

The results of the study seem to confirm E. Aronson's statement in which he claims that somebody who regards themselves as being resistant to persuasion does not indicate that they really are resistant to it [20]. The identification of this differentiation of Internet users' resistance was based on latent class analysis.

The analyzed problem has an interdisciplinary character. The analysis comprises various sciences, including marketing, management, and economics, as well as sociology and psychology. Each discipline undertakes research of this problem on the basis of its own assumptions, theoretical frameworks paradigms, terminology, and research methods. This poses a number of research challenges, but it also provides opportunities and incentives for interdisciplinary research. Objective cognition and explanation of a complex issue-which is undoubtedly the paper's title problem-provides an incentive for integrating scientific disciplines and specific research areas and creating a synthesis comprising marketing, management, and economics. Answers to questions posed by marketing and economic sciences related to human behavior in an economic system are frequently offered by sciences "beyond economics".

This study has led to new and interesting cognitive science conclusions, contributing to research on the impact of advertising on consumer behavior. In addition, the study is significant from a social perspective. The obtained results can be treated as a signal confirming the necessity of introducing 
state regulation aimed to prevent online advertising manipulation, as well as ethical standards and self-regulation in the advertising industry. Similar conclusions are formulated by S. Dahl and K. Mortiner [95], as well as G.A. Akerlof and R.J. Schiller:

"Just as our computers need protection against malware, so too we need protection against phishing for phools more broadly defined". [75]

Interestingly, the greatest advocates of this approach are the representatives of the most conscious and experienced class, who solve their problems "on their own". It should also be noted that the findings of this research can be put into practice by companies. This particularly refers to the significance of trust in the opinions expressed by other Internet users in social media. In this context, the use of artificial intelligence and Big Data in e-marketing and the development of automatization and advanced content personalization techniques can be accompanied by a warning about "information abuse temptation" in company ads and their organization in the media space, as well as, consequently, an attempt to use advertising techniques to manipulate and affect consumer behavior.

The research presented in this paper has certain limitations. In a methodical dimension, they relate to sample size and the use of only one (but significant and adequate) research method. In designing further research, we recommend extending the research sample, random choice of respondents, and the application of methodical triangulation. A significant and interesting trend in future research can be an attempt to capture differences in the perception of the discussed problem from an individual perspective and at the level of digital competences, and to engage the community of international researchers. On the basis of such substantive and methodical assumptions, research studies can seek to identify, explore, and assess moral hazard (information abuse) in companies' advertising strategies as well as adverse selection in consumer purchase decisions in the increasingly uniform digital market of the contemporary world.

Author Contributions: The two authors designed the research, conducted the research and investigation process, contributed to the data analysis, and participated in the preparation and revision of the manuscript. All authors have read and agreed to the published version of the manuscript.

Funding: This research was funded by the NCN (National Center of Science) grant: The asymmetry of information in online advertising and e-consumer behavior manipulation (2018/29/B/HS4/00563).

Conflicts of Interest: The authors declare no conflict of interest.

\section{References}

1. LaTour, M.S.; LaTour, K.A. Positive mood and susceptibility to false advertising. J. Advert. 2009, 38, 127-142. [CrossRef]

2. Trivedi, K.; Trivedi, P.; Goswami, V. Sustainable Marketing Strategies: Creating Business Value by Meeting Consumer Expectation. Int. J. Manag. Econ. Soc. Sci. 2018, 7, 186-205.

3. Certified, B. Corporation. Available online: https://www.bcorporation.net (accessed on 3 October 2020).

4. Gordon, R.; Carrigan, M.; Hastings, G. A framework for sustainable marketing. Mark. Theory 2011, 11, 143-163. [CrossRef]

5. Brundtland, G.; Komiyama, H.; Takeuchi, K. Sustanability Science: Building a new discipline. Sustain. Sci. 2006, 1, 1-6.

6. SDG-2030, Action Agenda (AAAA). Available online: http:/www.un.org./esa/ffd.wp-content/uploads/2015/ 08/AAAAOutcome.pdf (accessed on 9 September 2020).

7. Aaker, D.A.; Stayman, D.M. Measuring Audience Perceptions of Commercials and Relating Them to Ad Impact. J. Advert. Res. 1990, 30, 7-17.

8. Owen, L.; Lewis, C.; Auty, S.; Buijzen, M. Is Children's Understanding of Nontraditional Advertising Comparable to Their Understanding of Television Advertising? J. Public Policy Mark. 2013, 32, $195-206$. [CrossRef]

9. Wright, P. Factors Affecting Cognitive Resistance to Advertising. J. Consum. Res. 1975, 2, 1-9. [CrossRef]

10. Wright, P.; Friestad, M.; Boush, D.M. The Development of Marketplace Persuasion Knowledge in Children, Adolescents, and Young Adults. J. Public Policy Mark. 2005, 24, 222-233. [CrossRef] 
11. Brettel, M.; Spilker-Attig, A. Online advertising effectiveness: A cross-cultural comparison. J. Res. Interact. Mark. 2010, 4, 176-196. [CrossRef]

12. Park, C.H.; Kim, Y.G. Identifying key factors affecting consumer purchase behavior in an online shopping context. Int. J. Retail Distrib. Manag. 2003, 31, 16-29. [CrossRef]

13. Sanak-Kosmowska, K. Rola Serwisów Społecznościowych w Komunikacji Marketingowej Marki; Wydawnictwa Drugie: Warszawa, Poland, 2018.

14. Chapoton, B.; Régnier Denois, V.; Nekaa, M.; Chauvin, F.; Flaudias, V. Social Networking Sites and Perceived Content Influence: An Exploratory Analysis from Focus Groups with French Adolescents. Int. J. Environ. Res. Public Health 2020, 17, 7025. [CrossRef] [PubMed]

15. Chu, S.C.; Kim, Y. Determinants of consumer engagement in electronic world-of-mouth (eWOM) in social networking sites. Int. J. Advert. 2011, 30, 47-75. [CrossRef]

16. Kotler, P.H.; Kartajaya, H.; Setiawan, I. Marketing 4.0. Moving from Traditional to Digital; John Wiley \& Sons: Hoboken, NJ, USA, 2018.

17. Kotler, P.H.; Keller, K.L. Marketing Management; Pearson: London, UK, 2018.

18. Young, M. Ogilvy on Advertising in the Digital Age; Carlton Books: London, UK, 2017.

19. Schwab, K. The Fourth Industrial Revolution; World Economic Forum: Geneva, Switzerland, 2016.

20. Aronson, E. The Social Animal; Worth/Freeman: New York, NY, USA, 2011.

21. Barney, D. The Network Society. Key Concept Series; Polity: Cambridge, UK, 2004.

22. Castells, M. The Rise of the Network Society; Blackwell: Cambridge, UK, 2009.

23. Mazurek, G.; Tkaczyk, J. (Eds.) The Impact of the Digital World on Management and Marketing; Poltext: Warszawa, Poland, 2016.

24. McLuhan, M. The Gutenberg Galaxy: The Making of Typographic Man; University of Toronto: Toronto, ON, Canada, 1962.

25. Pratkanis, A.R.; Aronson, E. Age of Propaganda: The Everyday Use and Abuse of Persuasion; Henry Holt: New York, NY, USA, 2001.

26. Skinner, C.H. Digital Human: The Fourth Revolution of Humanity Includes Everyone; John Wiley \& Sons: Hoboken, NJ, USA, 2018.

27. Cialdini, R. Influence. Science and Practice; Allyn \& Bacon: Boston, MA, USA, 2008.

28. Danciu, V. Manipulative marketing: Persuasion and manipulation of the consumer through advertising. Theor. Appl. Econ. 2014, 21, 19-34.

29. De Pelsmacker, P.; Geuens, M.; Van den Bergh, J. Marketing Communications. A European Perspective; Pearson Education: Harlow, UK, 2007.

30. Foxall, G.R.; Goldsmith, R.E.; Brown, S. Consumer Psychology for Marketing; Thomson: London, UK, 1998.

31. Gass, R.H.; Seiter, J.S. Persuasion: Social Influence and Compliance Gaining; Routledge: New York, NY, USA, 2015.

32. Kahneman, D. Thinking, Fast and Slow; MacMillan: London, UK, 2011.

33. Ogilvy, D. Ogilvy on Advertising; Carlton Books: London, UK, 2007.

34. Perloff, R.M. The Dynamics of Persuasion: Communication and Attitudes in the Twenty-First Century; Routledge: London, UK, 2020.

35. Rodgers, S.; Thorson, E. Advertising Theory; Routledge: New York, NY, USA, 2012.

36. Bruhn, M. Kommunikationspolitik, Systematischer Einsatz der Kommunikation für Unternehmen; Verlag Franz Vahlen: München, Germany, 2013.

37. Hoffman, D.L.; Novak, T.P. Marketing in Hypermedia Computer-Mediated Environments: Conceptual Foundations. J. Mark. 1996, 60, 50-68. [CrossRef]

38. Minton, E.; Lee, C.H.; Orth, U.; Chung-Hyun, K.; Kahle, L. Sustainable Marketing and Social Media. J. Advert. 2012, 41, 69-84. [CrossRef]

39. Riedl, J.; Busch, M. Marketing-Kommunikation in Online-Medien. Market. Z. Forsch. Praxis 1997, 19, $163-176$. [CrossRef]

40. Wiktor, J.W. Marketing communication in hypermedia computer-mediated environments vs the paradigm of a network society. Int. J. Bus. Glob. 2016, 17, 287-298. [CrossRef]

41. Maráková, V. Marketingová komunikácia v cestovnom ruchu; Wolters Kluwer: Bratislava, Slovakia, 2016.

42. Wiktor, J.W. Komunikacja Marketingowa. Modele, Struktury, Formy Przekazu; Wydawnictwo Naukowe PWN: Warszawa, Poland, 2013. 
43. Ромат, Э.; Сендероов, Д. Маркетинговые Коммуникации; Санккт -Петербуург: ПИТЕР, Russia, 2018.

44. Juska, M.J. Integrated Marketing Communication. Advertising and Promotion in a Digital World; Routledge: New York, NY, USA, 2017.

45. Eagle, L.; Dahl, S.; Czarnecka, B.; Lloyd, J. Marketing Communications; Routledge: London, UK, 2014.

46. Falkheimer, J.; Heide, M. Strategic Communication: An Introduction; Routledge: London, UK, 2018.

47. Percy, L. Strategic Integrated Marketing Communications; Routledge: London, UK, 2014.

48. Dillard, J.P.; Shen, L. The Sage Handbook of Persuasion. Developments in Theory and Practice; Sage Publications: London, UK, 2002.

49. Keer, G.; Richards, J. Redefining advertising in research and practice. Int. J. Advert. 2020, 1-24. [CrossRef]

50. O'Keefe, J.D. Persuasion: Theory and Research; Sage: Newbury Park, CA, USA, 1990.

51. Prislin, R.; Crano, W.D. A history of social influence research. In Handbook of the History of Social Psychology; Kruglanski, A.W., Stroebe, W., Eds.; Psychology Press: Washington, DC, USA, 2012.

52. Stiff, J.B. Persuasive Communication; Guilford Press: New York, NY, USA, 1994.

53. Chen, L.; Li, W.; Chen, H.; Geng, S. Detection of Fake Reviews: Analysis of Sellers' Manipulation Behavior. Sustainability 2019, 11, 4802. [CrossRef]

54. Doliński, D. Techniki Wpływu Społecznego; Scholar: Warszawa, Poland, 2005.

55. Petty, R.E.; Cacioppo, J.T. Attitudes and Persuasion: Classic and Contemporary Approaches; WCB: Des Moines, IA, USA, 1981.

56. Roskos-Ewoldsen, D.R.; Fazio, R.H. The accessibility of source likebility as a determinant of persuasion. Personal. Soc. Psychol. Bull. 1992, 38, 137-143.

57. Russell, J.T.; Lane, W.R. Kleppner's Advertising Procedure; Prentice Hall: Upper Saddle River, NJ, USA, 2002.

58. Akerlof, G.A. The Market for "Lemons": Qualitative Uncertainty and the Market Mechanism. Q. J. Econ. 1970, 84, 488-500. [CrossRef]

59. Hillier, B. The Economics of Asymmetric Information; MacMillan Press: London, UK, 1997.

60. Sandmo, A. Asymmetric Information and Public Economics: The Mirrlees-Vickrey Nobel Prize. J. Econ. Perspect. 1999, 3, 165-180. [CrossRef]

61. Spremann, K. Asymetrische Information. Zeischrift für Betriebwietschaft 1999, 5/6, 561-586.

62. Barkley Rosser, J.A., Jr. Nobel Prize for Asymmetric Information: The economic contributions of George Akerlof, Michael Spence and Josef Stieglitz. Rev. Political Econ. 2003, 15, 3-21. [CrossRef]

63. Deshmukh, S. The Effect of Asymmetric Information on Dividend Policy. Q. J. Bus. Econ. 2005, 44, $107-127$.

64. Dixit, A.; Nalebuff, B. The Art of Strategy: A Game Theorist's Guide to Success in Business and Life; W. W. Norton \& Company: New York, NY, USA, 2010.

65. Forlicz, S. Niedoskonała Wiedza Podmiotów Rynkowych; PWN: Warszawa, Poland, 2001.

66. Gajewski, J.F. Friction et Asymétrie D'information Sur les Marchés D'action; Economica: Paris, France, 2000.

67. Garbe, R. Die Kraft der Informationsasymmetrie in Großen Organization: Immer wieder Prinzipal und Agent; Iger Verlag RWS: Hamburg, Germany, 2017.

68. Illing, G. Geld und Asymmetrische Information; Springer: Berlin/Heidelberg, Germany, 1985.

69. Lehmann, E. Asymmetrische Information und Werbung; Springer: Hamburg, Germany, 1999.

70. Nestorowicz, R. Asymetria Wiedzy a Aktywność Informacyjna Konsumentów na Rynku Produktów Żywnościowych; Wydawnictwo Uniwersytetu Ekonomicznego w Poznaniu: Poznań, Poland, 2017.

71. Ragotzky, S. Unternehmensverkauf und Asymetrische Information; Europäische Hochschulschriften Peter Lang: Frankfurt am Main, Germany, 2003.

72. Evans, N.J.; Phua, J.; Lim, J.; Jun, H. Disclosing Instagram Influencer Advertising: The Effects of Disclosure Language on Advertising Recognition, Attitudes, and Behavioral Intent. J. Interact. Advert. 2017, 17, 138-149. [CrossRef]

73. Reevers, R. Reality in Advertising; Widener Classics: Harvard, MA, USA, 1961.

74. Samuelson, W.F.; Marks, S.G. Managerial Economics; John Wiley \& Sons: New York, NY, USA, 2014.

75. Akerlof, G.J.; Shiller, R.J. Phishing for Phools. The Economics of Manipulation and Deception; Princeton University Press: Princeton, NJ, USA, 2015.

76. Gordon, D. Phishing for Phools: The Economics of Manipulation and Deception by George A. Akerlof and Robert J. Shiller; In The Austrian; 2016; Volume 2, pp. 12-14. Available online: https://cdn.mises.org/The\%20Austrian\% 20vol\%202\%20no\%201\%202016.pdf (accessed on 20 October 2020).

77. Eagle, L.; Dahl, S. Marketings Ethics \& Society; Sage Publication Ltd.: London, UK, 2015. 
78. Tokarz, M. Argumentacja, Perswazja, Manipulacja; Wykłady z Teorii Komunikacji; GWP: Gdańsk, Poland, 2010.

79. Friedman, M.; Friedman, R. Free to Choose: A Personal Statement; Harcourt: San Diego, CA, USA, 1980.

80. Kaptein, M.; Markopoulos, P.; De Ruyter, B.; Aarts, E. Can You Be Persuaded? Individual Differences in Susceptibility to Persuasion. Multimed. Modeling 2019, 115-118. [CrossRef]

81. Byung-Do, K.; Srinivasan, K.; Wilcox, R.T. Identifying price sensitive consumers: The relative merits of demographic vs. purchase pattern information. J. Retail. 1999, 75, 173-193.

82. Zhuang, M.; Cui, G.; Peng, L. Manufactured opinions: The effect of manipulating online a product reviews. J. Bus. Res. 2018, 87, 24-35. [CrossRef]

83. Bryman, A. Social Research Methods; Oxford University Press: New York, NY, USA, 2008.

84. Bosnjak, M.; Tuten, T.L. Classifying Response Behaviours in Web-based Surveys. J. Comput. Mediat. Commun. 2001, 3. [CrossRef]

85. Linzer, D.A.; Lewis, J.B. poLCA: An R Package for Polytomous Variable Latent Class Analysis. J. Stat. Softw. 2011, 41, 1-29.

86. Lazarsfeld, P.F. The Interpretation and Mathematical Foundation of Latent Class Structure Analysis; Measurement and Prediction; Princeton University Press: Princeton, NJ, USA, 1950.

87. Lazarsfeld, P.F. Latent Structure Analysis. In Psychology: A Study of a Science; McGraw-Hill: New York, NY, USA, 1959.

88. Anderson, T.W. Some Scaling Methods and Estimation Procedures in the Latent Class Model, Probability and Statistics; Grenander, U., Ed.; John Wiley \& Sons: New York, NY, USA, 1959.

89. Goodman, L.A. Exploratory latent structure analysis using both identifiable and unidentifiable models. Biometrika 1974, 61, 215-231. [CrossRef]

90. Collins, L.; Lanza, S. Latent Class and Latent Transition Analysis: With Applications in the Social, Behavioral, and Health Sciences; John Wiley \& Sons: Hoboken, NJ, USA, 2010.

91. Massaglia, S.; Merlino, V.M.; Borra, D.; Bargetto, A.; Sottile, F.; Peano, C. Consumer Attitudes and Preference Exploration towards Fresh-Cut Salads Using Best-Worst Scaling and Latent Class Analysis. Foods 2019, 8, 568. [CrossRef] [PubMed]

92. Rost, J.; Langeheine, R. (Eds.) Applications of Latent Trait and Latent Class Models in the Social Sciences; Waxmann Publishing Co.: Munster, Germany; New York, NY, USA, 1997.

93. White, R.; Murphy, T.B. Bayes LCA: An R Package for Bayesian Latent Class Analysis. J. Stat. Softw. 2014, 61, 1-28. [CrossRef]

94. Amblee, N.; Bui, T. Harnessing the Influence of Social Proof in Online Shopping: The Effect of Electronic Word of Mouth on Sales of Digital Microproducts. Int. J. Electron. Commer. 2011, 16, 114-191. [CrossRef]

95. Dahl, S.; Mortimer, K. Legislation, regulation and ethics. In Marketing Ethics and Society; Eagle, L., Dahl, S., Eds.; Sage: London, UK, 2015; pp. 265-272.

Publisher's Note: MDPI stays neutral with regard to jurisdictional claims in published maps and institutional affiliations.

(C) 2020 by the authors. Licensee MDPI, Basel, Switzerland. This article is an open access article distributed under the terms and conditions of the Creative Commons Attribution (CC BY) license (http://creativecommons.org/licenses/by/4.0/). 